\title{
Gamification-supported Exploration and Practicing for Automotive User Interfaces and Vehicle Functions
}

\author{
Stefan Diewald, Andreas Möller, Tobias Stockinger, Luis Roalter, \\ Marion Koelle, Patrick Lindemann and Matthias Kranz
}

\begin{abstract}
When driving an unknown car, the interaction with its user interfaces and the operation of (comfort) vehicle functions can be very challenging and thus cause safety concerns. However, this problem can be overcome already with a short learning and practicing phase. For this reason, we analyze the potential of gamification for exploring and practicing the use of automotive user interfaces and vehicle functions. Based on the analysis of available examples, we have created a gamified automotive exploration and practicing framework. The framework allows exploring vehicle functions and user interfaces in real vehicles as well as in applications for mobile devices. By reflecting on the results of a first user study with the framework, we deliver a set of guidelines for designing and evaluating gamified applications for the automotive domain, which can serve as a support for future developments.
\end{abstract}

\footnotetext{
Stefan Diewald, Andreas Möller, Luis Roalter

Technische Universität München, Distributed Multimodal Information Processing Group, Arcisstr. 21, 80333 Munich, Germany, e-mail: stefan.diewald@tum.de, andreas.moeller@tum.de,roalter@tum.de

Tobias Stockinger, Marion Koelle, Patrick Lindemann, Matthias Kranz University of Passau, Innstr. 43, 94032 Passau, Germany, e-mail: <firstname.lastname>@uni-passau.de
} 


\section{Introduction}

\subsection{Motivation}

People like gaming, winning, comparing, and sharing (Hsu and $\mathrm{Lu}$ 2004). This has been known for thousands of years and has been exploited in so-called serious games (Abt 2002) in many different areas such as the military, academics, medicine, or professional training (Zyda 2005). Serious games make use of the entertaining gaming effect to educate, train and inform their "players" (Michael and Chen 2005).

However, applications that are not framed in game scenarios can likewise benefit from gamification. Especially with the success of the location-based application Foursquare in 2010, which has made heavy use of game design elements in its application, the research and design community started to pay more attention to the so-called "gamification" of non-gaming applications. Since then, the buzzword "gamification" stands for the method for boosting the users' motivation, commitment, and participation. Deterding et al. researched the current use of gamification and proposed the following definition: "Gamification is the use of game design elements in non-game contexts" (Deterding et al. 2011). However, a discussion about the term "gamification" has recently emerged. Some researchers and game designers think that many companies abused gamification by adding an independent "game layer" to an existing application and/or by using extrinsic rewards to achieve short-term success. The use of game design elements in non-game contexts with the goal of achieving long-term effects based on intrinsic motivation is often referred to as "gameful design" (Deterding et al. 2011). The term "gameful design" shall emphasize the fact that game elements should be part of the concept already during design and should not be added by an independent "gamification layer." Applications equipped with game design elements we call "gamified" applications.

Since gamification can arouse sustainable motivation and strong commitment, it has found its way into the automotive domain. Automotive manufacturers are currently applying gamification approaches 
for three prominent use cases: marketing (Tillström 2012), eco-driving (Inbar et al. 2011), and driving safety (Shi et al. 2012). While marketing aims at convincing customers to buy a certain car, eco-driving and driving safety applications are integrated in the vehicles' infotainment systems. These in-vehicle applications try to educate the drivers by awarding points and badges for safe and ecological driving.

In our research, we investigate a new use case for gamification in the automotive domain: exploration of automotive user interfaces and practicing of vehicle functions. In a recent study ${ }^{1}$, it has been found that cars ranging from compact to premium level are suffering from user experience problems. Misplaced or too many controls, misleading labels, too deeply nested menus, and unreliable speech recognition are demotivating the users. In addition to the non-self-explanatory interfaces, users are often avoiding manuals for technical systems (Novick and Ward 2006). These circumstances entail unsatisfied customers that are able to use only a fraction of their (often expensively bought) cars' functions ${ }^{2}$. In addition, a study of the U.S. National Highway Traffic Safety Administration (NHTSA) has revealed that secondary and tertiary tasks in vehicles, such as adjusting the radio and other devices integral to the vehicle, contribute to over $22 \%$ of all investigated crashes and near-crashes (NHTSA 2009). However, it has been shown that many of these problems can be overcome by practicing (Rouzikhah et al. 2013).

Therefore, we propose a gamification-supported framework for exploring and practicing automotive user interfaces and vehicle functions. The framework consists of a mobile application that recreates the vehicle cockpit for allowing offline exploration and training, and an in-vehicle application that replaces the owner's manual and provides hints and tips for the driver.

\footnotetext{
${ }^{1}$ http://www.wiwo.de/technologie/auto/funktionen-im-auto-unsere-autos-sind-zu-schwer-zu-bedienen/7860276.html, last accessed 13 May 2013

${ }^{2} \mathrm{http} / /$ www.wired.com/autopia/2013/04/car-tech-failing/, last accessed 12 May 2013
} 


\subsection{Contribution}

In this chapter, we contribute a review of gamified applications in the automotive domain and an overview over gamified learning environments. By examining the gathered examples, we point out potential limitations and challenges of gamification on both considered areas.

Based on these findings, we contribute the concept and implementation of a gamified framework for exploration and practicing of automotive user interfaces and vehicle functions. Results of a first user study and experiences gathered during the development are summarized and serve as basis for some first guidelines that can support future researches in designing and evaluating gamified automotive applications.

\subsection{Chapter Overview}

In Section 2, we first present the game design elements and game mechanics that are commonly used in gamified systems. With this knowledge at hand, we analyze existing gamified examples in different automotive areas (Section 3) and briefly summarize important aspects of gamified learning applications (Section 4). In Section 5, the results of the analyses of Sections 3 and 4 are summarized to challenges and limitations of gamification. Based on these findings, we present the concept and implementation of our gamified framework for exploring and practicing automotive user interfaces and vehicle functions in Section 6. Parts of the framework have been evaluated in a user study. The study and its results are summarized in Section 7. In Section 8 , we compile guidelines for future gamified automotive application. The guidlines are based on our experiences from the development of the framework and from our experiment with the framework. Finally, we conclude by summarizing the presented ideas and by giving an outlook to our future work (Section 9). 


\section{Elements and Mechanics of Gamification}

In order to analyze the currently available applications, the basics of gamification are summarized in this section. For creating a sustainable effect and lasting commitment, the source of motivation is important. Intrinsic motivation comes from the activity itself, whereas extrinsic motivation comes from the outside (Deci et al. 1972). While intrinsic motivation seems to be desirable, one also has to think about the users that do not get intrinsic reward solely from the activity. In that case, extrinsic rewards can substitute the missing initial intrinsic motivation. However, there is the danger that by giving too much extrinsic reward, the intrinsic reward diminishes (Deci et al. 2001) and the person has to be kept in a reward loop forever (Zichermann and Cunningham 2011, p. 27). In order to create intrinsic motivation, according to McGonigal, four things need to be considered: satisfying work (consisting of a clear goal and next actionable tasks), the hope/experience of being successful, social connection, and meaning (McGonigal 2011, p. 53). Satisfying work and the experience or hope of being successful can be fulfilled by the characteristics of games (McGonigal 2011, p. 29ff):

- Goal: The sense of purpose. It focuses the users' attention and gives orientation.

- Rules: Limitations on how the goal can be achieved. They boost the users' creativity, foster strategic thinking, and help define the next actionable tasks.

- Feedback system: How close is the user to the goal? (progress bar, points, levels)

- Voluntary participation: Freedom to enter the game. Leads to acceptance of rules and feedback.

The goal of social connection can be achieved by involving friends via social networks or by teaming up people that have a common unique goal. McGonigal claims that meaning can occur when users are part of something "epic" (McGonigal 2011, p. 61ff). That means, for example, that they can contribute to a superior goal that is carried out and lasts for a longer time (e.g., fighting climate change). People need something to master that adapts to their progress and their skills (Zichermann and Cunningham 2011, p. 29). All of these factors make 
up games and, as a result, they are important parts of gameful design. In our analysis, we concentrate on game mechanics, since these are the basic components of a game (Hunicke et al. 2004). According to Zichermann and Cunningham (2011), the seven primary game mechanics are points, levels, leaderboards, badges, onboarding, challenges/quests, and engagement loops. 


\section{Gamification in the Automotive Domain}

In this section, examples of automotive applications are examined. The analysis is split up in two parts: applications outside vehicles and applications for in-vehicle usage (Diewald et al. 2013). The analysis focuses on applied gamification elements and includes a view on the chosen type of motivation.

\subsection{Gamified Automotive Applications outside Vehicles}

\subsubsection{Automotive Marketing with Gamified Applications}

Outside vehicles, the main areas of application are marketing and brand forming. By applying gamification, the automotive manufacturers want to create customers that are more attracted to their brands and more profitable.

An example is Volkswagen's BlueMotion Roulette ${ }^{3}$. In order to promote the lower fuel consumption of their new BlueMotion car, Volkswagen created a game in which users could win the car by guessing how far it can drive with one tank of fuel. However, instead of creating a simple competition where the participants could enter their guesses, they took a real car and drove along a selected road in Norway. The route was visualized on Google Maps and the users could bet via their Facebook account on a single road segment that had not been taken by another player. On the competition day, the players could follow the car's journey live on the map and discuss it on $\mathrm{Fa}$ cebook. Since each user could only bet once, one could maximize her/his chance of winning by finding out more about the car and its fuel consumption before entering.

It can be assumed that for most users the possible extrinsic reward of winning a car was the decisive factor for joining the "game". However, the gaming experience caused by the roulette association, the easy onboarding by presenting the facts about the car and the game in a short simulation, and the challenge to beat other real players also

${ }^{3}$ http://www.bluemotion.no/, last accessed May 29, 2013 
caused intrinsic motivation for many players, which can be seen by the large amount of Facebook likes and comments ${ }^{4}$.

Many applications reward users with badges etc. just for driving around without having a clear goal. For example, the social driving application Smileage ${ }^{5}$ rewards its users for meeting other vehicles that are also using the Smileage application. Another example is MyFord Mobile, which rewards its users, for instance, for driving 100,000 miles with an electric vehicle. The objective of such applications can be seen in marketing, since its main purpose is sharing these badges on different social networks.

\subsubsection{Gamified Speed Monitoring Applications}

The speed camera lottery ${ }^{6}$ was designed to reward people for doing the right thing. Instead of just taking a picture of speeding cars, a modified traffic camera would photograph all passing cars. A portion of the fines from the speeders would be pooled in a lottery in which each of the law-obeying car owners would have a lottery ticket. A demo in Stockholm lasting for three days resulted in a drop of the average speed from 32 kilometers per hour to 25 kilometers per hour. In this example, the motivation is mainly caused by the extrinsic reward, which is the chance of winning the lottery. A deeper analysis of this application is difficult, since there are no numbers for comparing the effect against a standard traffic camera or for a longer period. However, it can be assumed that this gamified traffic camera could also lead to undesired effects. For instance, more traffic could occur on the road since people want to enter the lottery. Gamified road signs ${ }^{7}$, which display friendly or unhappy smilies depending on whether the speed limit is obeyed or not, are another example of applied gamification. The effect of these signs is based on instantaneous feedback and social pressure as all passersby can see the breach of rules.

\footnotetext{
${ }^{4} \mathrm{https}$ ://www.facebook.com/BlueMotionRoulette, last accessed May 29, 2013

${ }^{5} \mathrm{http}: / /$ smileage.vw.com/, last accessed June 5, 2013

${ }^{6} \mathrm{http}: / /$ wheels.blogs.nytimes.com/2010/11/30/speed-camera-lottery-wins-vw-fun-theory-contest, last accessed May 30, 2013

${ }^{7}$ http://www.smileysid.co.uk/, last accessed June 5, 2013
} 


\subsection{Gamified Automotive Applications in Vehicles}

The following sections describe gamified applications that are intended for use in real vehicles.

\subsubsection{Navigation and Efficient Driving}

A popular gamified application is the community-based traffic and navigation mobile application $W_{a z}^{8}$. It rewards its users for mapping uncharted areas and reporting traffic issues. Points and leaderboards create a competition between users. However, these points are not only used for comparing with other users, they are also used as a confidence score for a user's contribution. The top $x$ percent of users are further upgraded from Waze Grown-Ups to Waze Warriors, Waze Knights, or Waze Royalties. The contribution to an active community that has the goal to make driving more efficient partly creates an intrinsic motivation, which can cause users to diverge from their route to join in ${ }^{9}$

The I-GEAR (incentives and gaming environments for automobile routing) project aims at changing users' behavior in order to reduce traffic congestion (McCall and Koenig 2012). For example, users could be rewarded for taking a later bus or going to a suburb shopping mall instead of the one in the city center with free bus tickets or discounts at a store in the selected suburb mall. In addition to the immediate rewards, users also would get points for sticking to the application's recommendations. These points could be converted into material rewards later. Drivers could also team up and gather points to win prizes like free car insurance for one year when their team has the highest score at the end of the year. This project sets a lot on extrinsic rewards.

\subsubsection{Safe Driving}

The mobile application Driving Miss Daisy by Shi et al. (2012) performs a gamified driving style assessment. Instead of just showing a

\footnotetext{
${ }^{8} \mathrm{http}: / /$ www.waze.com/, last accessed June 4, 2013

${ }^{9} \mathrm{http} / / / w w w . t e c h n o l o g y r e v i e w . c o m / n e w s / 422583 /$ social-surveillance-yields-smarter-directions/page/2/, last accessed May 28, 2013
} 
score of points, the performance is evaluated by a virtual passenger on the backseat ('Miss Daisy') who cheers or whimpers depending on the driving performance. In addition, a game summary is presented at the end of a drive. Besides the instantaneous feedback over thumbsup and thumbs-down, the driver can earn virtual money on each drive, which is accumulated over multiple rounds for comparison with other players. The application has several levels of difficulty which are increased based on the former performance. The performance of a drive can be compared to historical drives on the same route of the player $\mathrm{him} /$ herself (self-competition), and with the performance of other players (public competition).

CleverMiles ${ }^{10}$ is based on an external device that has to be connected with the vehicle's on-board diagnostics II (OBD-II) port. The device logs and analyzes the driving, and when safe driving is detected, the user gets CleverPoints that can be redeemed against products from different partners. In order to improve the players' driving, the system displays driving style recommendations. The application further allows users to share the driving performance data with Facebook friends and other drivers. Since the application is still in closed beta-trial, no information about the effectiveness is available so far.

\subsubsection{Eco-driving}

Gamified eco-driving applications can be found in many cars. An example is Ford's SmartGauge with EcoGuide"1, which was developed for hybrid vehicles. It informs the user about the current state and efficiency level of the vehicle's drive. When the car is driven at the most efficient level, "efficiency leaves" are growing on the right part of the dashboard as a reward for the user. Other examples are the color switching eco-gauge of the Chevrolet Volt, or Kia's ECOdynamics system $^{12}$ which offers different setups that challenge the driver to get the best economy rating. With Fiat's eco:Drive ${ }^{13}$, drivers can analyze

\footnotetext{
${ }^{10} \mathrm{http}: / / \mathrm{www} . c l e v e r m i l e s . c o m /$, last accessed May 20, 2013

${ }^{11} \mathrm{http}: / /$ stanfordbusiness.tumblr.com/post/32317645424/whygamification-is-really-powerful, last accessed May 24, 2013

${ }^{12} \mathrm{http}: / /$ thenextweb.com/shareables/2012/09/22/can-kias-gamification-change-way-drive-cars/, last accessed May 24, 2013

${ }^{13} \mathrm{http}$ ://www2.fiat.co.uk/ecodrive/, last accessed August 19, 2013
} 
their eco-driving-related behavior in real-time or afterwards at home. In addition to a score in form of an eco:Index, drivers can earn eco:Badges and contribute with their savings to create a better virtual place called eco:Ville.

The examined eco-driving applications challenge the users in a very emotional way (Tractinsky et al. 2011): Efficient eco-driving is indicated by green colors or by flourishing nature. In less efficient conditions, the displays are changing to the colors yellow or red and the leaves are disappearing. Thus, the user gets the feeling that something is broken or the vehicle is being mistreated. Competitive ecodriving can create a very strong intrinsic motivation. According to Deterding ${ }^{14}$, the gamified EcoChallenge application by Ecker et al. (2011) was so motivating that users would even go through red lights, which is an unintended behavior.

${ }^{14} \mathrm{http} / /$ en.slideshare.net/dings/pawned-gamification-and-its-discontents, slide 41, last accessed June 5, 2013 


\section{Gamified Learning and Exploration}

The second pillar of our automotive training framework is gamified learning and exploration. Since there are several examples and an extensive theoretical background analysis of gamified learning and training environments in Chapters "EDUCATION" and "From Market Place to Collusion Detection: Case Studies of Gamification in Education", we concentrate in our overview on the basics and only present a few examples that were considered in the conception phase of our proposed framework.

\subsection{Gamified Learning}

Already in the 1980s, Malone conducted experiments to find out what makes computer games fun and how this can be used for instructional computer games (Malone 1980). A thorough literature review on the positive impacts of gaming in learning, skill enhancement, and engagement settings has been presented by Connolly et al. (2013). Their review revealed that gamified learning application and serious games could boost knowledge acquisition, content understanding as well as increase the learner's affection and motivation. However, they also point out that the learning effectiveness is not automatically optimized by integrating game mechanics in learning applications.

When analyzing current examples of gamified learning environments (Muntean 2011; Simões et al. 2013), the use of game elements does not directly optimize the learning efficacy, but has mainly an impact on the learners' motivation (Domínguez et al. 2013). This is also an important factor for our framework, since our goal is getting the drivers to explore the user interface of the car and practice the usage of other vehicle functions as early as possible and best before the first drive with an unknown vehicle.

\subsection{Gamified Tutorials, Training and Exploration}

Gamification is also applied in tutorials for online services and computer applications. For example, the online cloud storage service 
Dropbox ${ }^{15}$ offers a tutorial mode that visualizes the users' 'learning' progress and rewards them with $250 \mathrm{MB}$ extra space when completing the tutorial. Additional space can be gained by completing other different tasks on a task list with progress display. By using the space as extrinsic reward, the service lets its users take over advertising on social networks etc.

GamiCAD is a gamified interactive tutorial system for first time AutoCAD users (Li et al. 2012). A comparison of the gamified tutorial with the default in-product interactive tutorial system revealed that users of the gamified version showed higher subjective engagement levels and completed test tasks $20 \%$ to $76 \%$ faster. Ribbon Hero $2^{16}$ is a game for learning Microsoft Office. The interactive tutorial consists of game setting challenges, which expose students step-by-step to more Office features. Students are encouraged to explore and learn on their own through points that are awarded for using basic functions as well as new functions that can be unlocked by completing challenges. Another motivation is the score sharing functions that allows publishing the current score via social media.

Orientation Passport by Fitz-Walter et al. (2011) is an example of a gamified mobile exploration application. The smartphone application is targeted at new students during their university orientation phase. It provides a digital orientation schedule of important student events accompanied with other helpful tools, such as an interactive campus map, a contact list, or a service information page. By checking into events, adding people to the contact list or answering questions to university services, the new students can unlock a maximum of 20 achievements. The results from a pilot study show that the achievement system motivated students to visit events and explore the campus and its services. However, downsides of the gamification were that some users only visited places once for unlocking an achievement and added random people as "friends" to their contact list to get the respective badge.

In order to enforce or train certain behaviors, aspects of behavioral economics can be combined with game elements. An example is the mobile application SmartPiggy (Stockinger et al. 2013). In this app,

\footnotetext{
2013

${ }^{15} \mathrm{https}: / / w w w . d r o p b o x . c o m / g e t s p a c e$, last accessed September 02,

${ }^{16} \mathrm{http}: / /$ www.ribbonhero.com/, last accessed August 19, 2013
} 
color-coded progress bars and badges support the task of saving money. In contrast to other implementations that only award badges to users, this application makes use of people's loss aversion and takes away gained badges when users fail to reach their goals.

Gamification cannot only persuade end-users to explore a system or application, but can also be used to explore the use and spread of technology. An example is the mobile application NFC Heroes (Kranz et al. 2013). The app is set in a trading card context and awards users with gadgets and points for documenting Near-Field Communication (NFC) technologies in their environment. The gathered data is used by researchers to explore the use of NFC and to measure the adoption of this technology.

Gamification is not only used for exploration and tutorials but also for different kinds of personal training. Example areas of mobile personal training applications are mobile fitness coaches (Kranz et al. 2013; McCallum 2012) or training applications for teaching methods in (higher) education (Möller et al. 2011). Especially for training applications, it is important to match the way of information presentation with the target audience. Expert users may not be willing to "play through a game" in order to access the information they are looking for. 


\section{Potential Limitations and Challenges of Gamification}

Looking at the examined examples, some challenges, and limitations of gameful design can be derived:

Games are voluntary and have no serious consequences: All of the applications examined here fulfil the voluntary nature. However, when gamification approaches areas such as electronic road pricing (Merugu et al. 2009), the voluntary nature could be limited when the driver has to either take part in the game or stay out of the game area. The competitive eco-driving example showed that the seriousness of traffic regulations could be surpassed by the intrinsic motivation coming from the gaming character. Applications that can have an influence on the driving style should be analyzed and extensively tested before they are released or integrated into vehicles.

Games abstract and simplify complex processes for a better gaming experience: In order to have a clearer relationship between the actions and the goal, games often simplify complex processes. However, when gamifying a real process, the precision and accuracy has to meet the requirements of the process. For example, a safe driving assessment application that only rewards the user based on rules like "drive slowly and do not brake" would not meet the requirements of safe participation in road traffic.

Games live from instant and unambiguous feedback: To encourage desired behavior, immediate and unambiguous feedback is important. However, during driving it can be very difficult to clearly present feedback without distracting the driver from the driving task. Although little icons in the dashboard or audio feedback could reduce the distraction, these could be ambiguous so the driver might know to have achieved something without knowing exactly what was achieved. A solution could be to shift the detailed explanation of the achievement to the next stop (e.g., at red lights).

How to phase out extrinsic rewards: When the motivation of a gamified application is mainly based on extrinsic rewards, it can be a difficult process to phase out these rewards. An approach could be to draw the "player's" attention to the intrinsic rewards one gets from using the application (e.g., focus on the social connection, the mas- 
tered challenges, or the learning progress). At the same time, the extrinsic rewards, which perhaps helped to attract the user, could be gradually reduced. The use and height of extrinsic rewards should be looked at in detail during the testing phase. The reward should not exceed a certain value that motivates users to execute unnecessary, rash, and unsafe driving maneuvers. 
6 Gamification-based Framework for Automotive User Interface Training

\subsection{Purpose of the Framework}

In order to investigate the potential of gamification for exploring automotive user interfaces and practicing the use of (comfort) vehicle functions, we developed a prototypical framework. We had the following research questions (RQs) in mind during the conception phase of the framework:

- RQ1: Does gamification have an influence on the training motivation of the subjects?

- RQ2: Does gamification during the training phase have an influence on the driving performance?

- RQ3: Does gamification influence the acceptance of recommendations given by a training system?

- RQ4: Will subjects perform safety-critical actions or even follow dangerous recommendations while driving in order to get a higher score from the framework?

While RQ1 (effects on motivation), RQ2 (effects on driving performance) and RQ3 (effect on acceptance) focus on positive aspects of gamification, RQ4 is intended to unveil possible negative gamification effects (see also Chapter NEGATIVE ASPECTS). The focus of our research is on the effect of gamification on the actual driving performance.

\subsection{General Functionality}

The framework is split up into two gamification-supported exploration and practicing modes (see Fig. 1). The first approach is the online mode that is running directly on the car's in-vehicle infotainment (IVI) system. Similar to classical step-by-step tutorials, the 'tutorial 

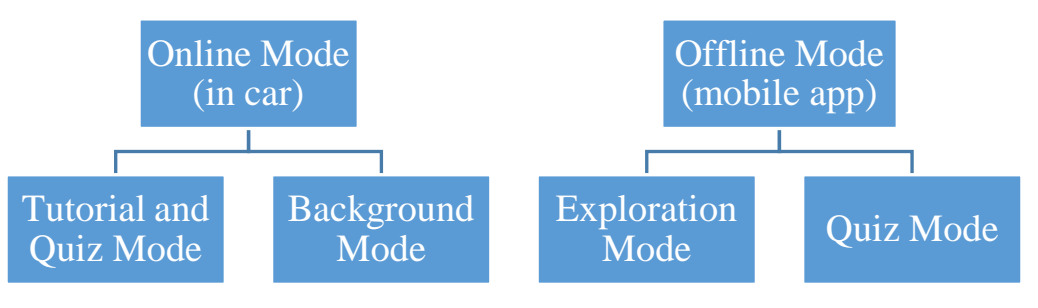

Fig. 1 The gamified exploration supports two modes: The online mode is running on the car's infotainment system, the offline mode is a mobile application for exploring the human machine interface (HMI) independent from the vehicle.

and quiz mode' guides the driver through the most important functions and awards points and badges with ongoing progress. Examples of trained functions are e.g. (1) adjusting the seat, (2) activating the hazard warning lights, (3) activating the adaptive cruise control, or (4) changing the radio station. The different learning units are interrupted by randomly selected quiz questions to rehearse already learned functions. By answering the questions within a certain time limit (in a safe driving situation and vehicular context, e.g. while the car is parked on private property), the user can earn bonus points. In contrast to the 'tutorial and quiz mode', which is only available when the car is parked, the 'background mode' is monitoring the driving while the car is moving. Whenever the user performs a secondary or tertiary task (Kern and Schmidt 2009), i.e. a task not directly related to driving, the driving behavior is analyzed in order to estimate the driver's distraction (for algorithms cf. Alonso et al. (2012)). At the end of the drive, the application calculates a score where $100 \%$ means that the driver is using the human machine interface (HMI) without noticeable distraction and $0 \%$ means that a high amount of distraction was detected for each performed secondary and tertiary task. As a result, the application suggests the driver what should be further practiced, and - when available - it suggests less distracting control alternatives, e.g. using the steering wheel volume control instead of the radio's volume control, or controlling a function via the voice command system. This score is also saved in a high score list. 


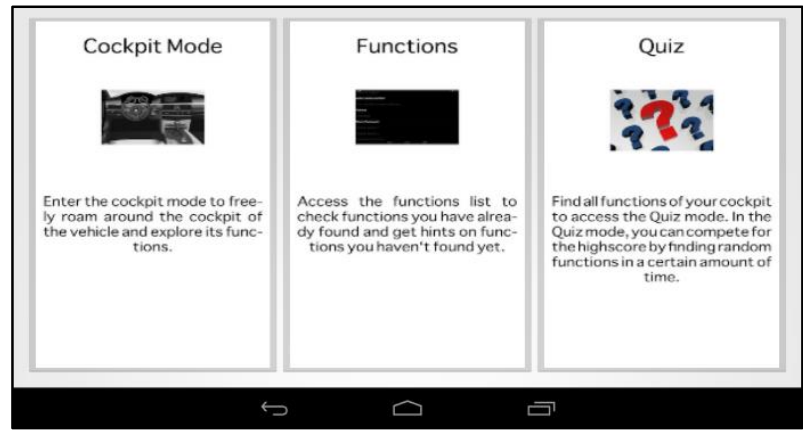

a. The main menu of the mobile application (offline mode). The cockpit mode allows free exploration of the vehicle's recreated cockpit (see Fig. 2 b).

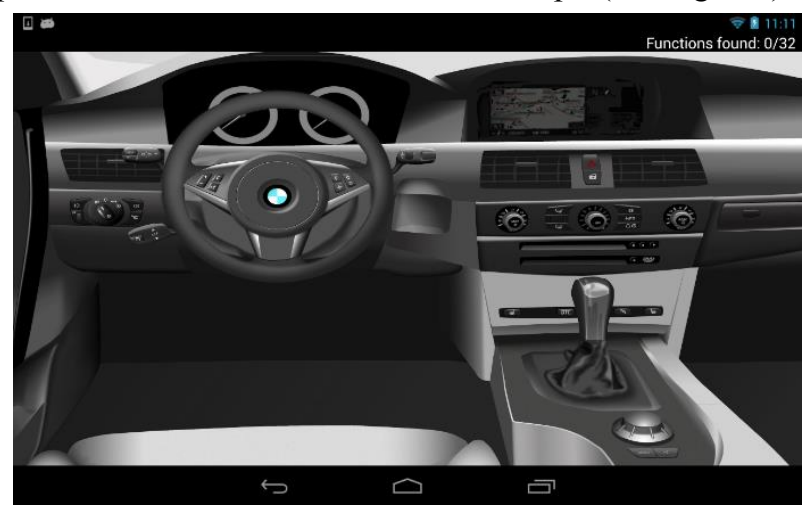

b. The cockpit mode of the mobile application. By clicking on an interactive element in the cockpit, the application shows usage details (see Fig. 2 c) and awards points to the user for newly found functions.

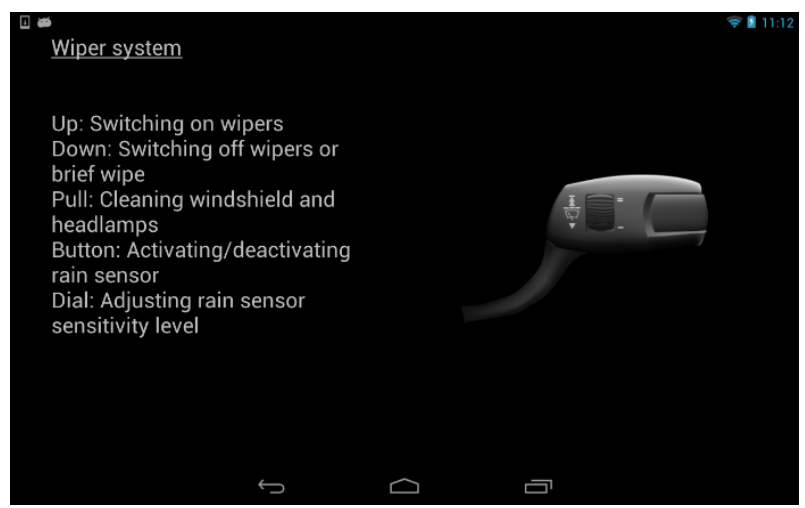

c. The details view explains the usage of the different interactive elements. There is also a walk-through for the vehicles infotainment menu. The example in this figure shows details on the wiper stalk switch.

Fig. 2 The three figures depict example screens of the mobile application that represents the offline mode of our proposed framework. 
The in-car mode is complemented by the offline mode that is realized as a mobile application for smartphones and tablet PCs. The 'exploration mode' allows exploring the human-machine interface. For newly identified functions, entries from a 'to explore' list are ticked off. In the 'quiz mode', random questions have to be answered by the user and points are awarded. When a set of questions on a special topic (e.g. the navigation system) has been successfully completed, an 'expert badge' is awarded to the user.

Both modes have been prototypically implemented. The online mode is implemented on a driving simulator based on a real car cockpit (see Fig. 3). By analyzing messages on the CAN (Controller Area Network) bus, the Java-based application can log the use of the car functions. In addition, the online mode also controls parts of the dashboard and the display on top of the center stack, which allows showing the feedback and the tutorial instructions directly on the car's built-in displays. The offline mode has been realized as mobile application for the Android platform. In both applications, the gamification elements can be turned off. This allows analyzing motivation and learning effects caused by gamification.

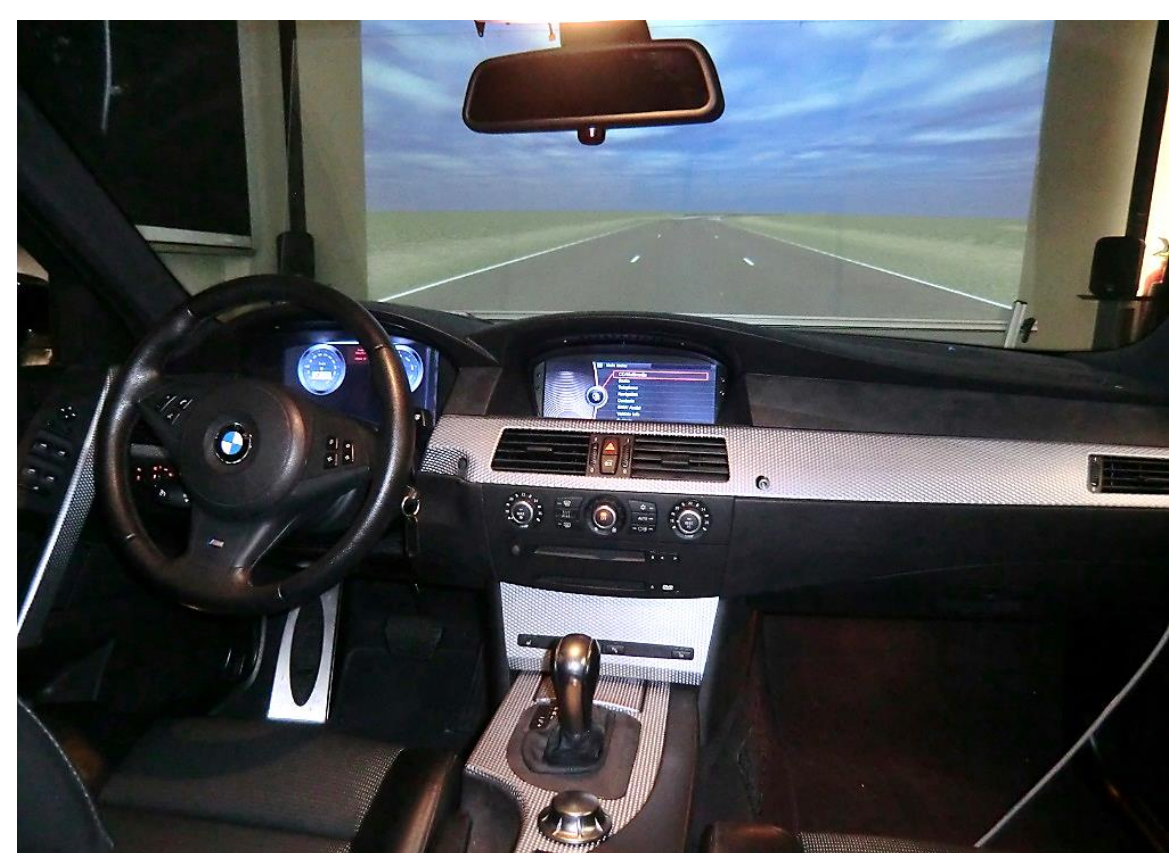

Fig. 3 The driving simulator used for the evaluation of the in-vehicle mode (online mode) of the framework. It is the real cockpit of a BMW 5-series. The framework controls parts of the dashboard and the display on top of the center stack, and can log most controls by monitoring the vehicle's CAN bus. 


\subsection{Sample Scenarios for the Gamified Automotive Training Framework}

\subsubsection{Interactive Tutorial for Car Buyers}

The proposed framework can be used in different scenarios. An example is its usage as an interactive tutorial for car buyers. The exploration and tutorial functionality of the online mode can be used as a replacement for the owner's manual. It could be automatically started before the first drive with the new car and later on started on demand whenever the driver needs help or wants to explore unknown control elements or menu points.

The offline mode could be interesting for buyers that are waiting for the delivery of their ordered car. Using the mobile application distributed by the car manufacturer could increase the buyer's excited anticipation and ensure that one knows how to use the car's functions right from the beginning.

\subsubsection{Guidance for Rental Car and Car Sharing Users}

Especially when driving an unknown vehicle - as is often the case with rental cars and car sharing vehicles - drivers can be overtaxed by the operation of tertiary car functions (Kern and Schmidt 2009). This could, for example, be overcome with a gamified preset mode that automatically starts when the driver enters the car. The online mode could be a virtual guide that shows the driver what one can adjust before the drive in order to have a less stressful drive. This could contain things like seat and mirrors adjustments, choosing the desired radio station, or setting the temperature of the air conditioning. Besides the intrinsic motivation of having a more convenient drive, possible extrinsic rewards could be the reduction of the insurance deductible or free car sharing minutes. 


\section{Evaluation of the Offline Mode Prototype}

In a first test, the offline mode prototype has been evaluated in order to answer the research questions presented in Section 6.1.

\subsection{Evaluation Setting and Methodology}

For evaluating the effects of the offline mode on the driving performance and vehicle function handling, subjects had to perform given secondary and tertiary tasks while driving in a simulator (see Fig. 3).

In order to measure the effect of the gamified training application, the participants were randomly divided into two groups (betweensubjects design):

(1) Without any training (control group).

(2) 10 minutes training with the offline mode (experiment group).

The metrics were time to task completion, lane deviation, subjective perceived workload, and ratings on a questionnaire. The perceived workload was measured by the NASA Task Load Index (NASA-TLX) questionnaire. The additional questionnaire asked about previous knowledge of the subjects and let them rate statements concerning their motivation as well as their perception of the gamefulness of the overall experiment.

\subsubsection{Tasks}

The driving task was the so-called Lane Change Task ${ }^{17}$ by Daimler (Harbluk et al. 2007). The maximum speed was set to $60 \mathrm{~km} / \mathrm{h}$. The secondary or tertiary tasks (operating tasks) to be performed by the subjects were shown on the lower part of the dashboard and were triggered automatically based on the driven distance. The subjects were instructed to focus on their speed, to perform the lane changes indicated by the simulation tool, and to keep their track. Although the participants should focus on driving safety, the displayed operating tasks should be performed as fast as possible. The operating tasks are summarized in Table 1.

${ }^{17} \mathrm{http}: / /$ sunburst.usd.edu/ schieber/ppt/MATTES2003powerpoint.pdf, last accessed September 23, 2013 


\begin{tabular}{|c|l|r|r|}
\hline $\begin{array}{c}\text { Task } \\
\text { No. }\end{array}$ & Task Description & $\begin{array}{l}\text { Start } \\
\text { Distance }\end{array}$ & $\begin{array}{l}\text { End } \\
\text { Distance }\end{array}$ \\
\hline T1 & $\begin{array}{l}\text { Increase radio volume via steering } \\
\text { wheel control }\end{array}$ & $400 \mathrm{~m}$ & $600 \mathrm{~m}$ \\
\hline T2 & $\begin{array}{l}\text { Change radio station via steering } \\
\text { wheel controls }\end{array}$ & $800 \mathrm{~m}$ & $1000 \mathrm{~m}$ \\
\hline T3 & Play CD: Sheryl Crow & $1200 \mathrm{~m}$ & $1800 \mathrm{~m}$ \\
\hline T4 & Activate the Active Cruise Control & $2000 \mathrm{~m}$ & $2400 \mathrm{~m}$ \\
\hline T5 & Start Navigation to 'Home' & $2600 \mathrm{~m}$ & $3300 \mathrm{~m}$ \\
\hline
\end{tabular}

Table 1 Overview of secondary and tertiary tasks users had to operate during the drive. The tasks were displayed on the lower part of the dashboard and were triggered automatically based on the driven distance. The task instruction was active from start distance to end distance and was hidden when the task was fulfilled.

The experiment began with a brief introduction for both groups. In a pre-experiment questionnaire, demographic data, driving experience and experience with technical systems such as smartphones were gathered.

Afterwards, the experiment group got a short introduction to the mobile application prototype (offline mode). Then, the subjects could freely explore and use the gamified application for a maximum of 10 minutes. The subjects in the control group immediately progressed with the driving task.

The driving task consisted of four laps (each around $3300 \mathrm{~m}$, $\sim 3.5$ minutes) in the Lane Change Task (LCT) simulation. In the first lap, subjects got an introduction to the simulation environment and to the Lane Change Task. In the second lap, ground truth data on the driving performance was recorded. During ground truth, no extra operating tasks had to be performed. For the last two laps, subjects had to perform the additional operating tasks (cf. Table 1) in parallel to the normal driving task. After the third lap, a summary of their operating performance in form of an automatically calculated score (composed of accomplished task score and time bonus) was presented to the subjects. Before they started the fourth lap, the experimenter told the subjects that the score is rather low and they could get into a highscore list when they perform the operation tasks faster and more accurate in the next lap. After each lap, subjects had to do a subjective assessment of their mental workload with the NASA Task Load Index questionnaire. 
After the driving experiment, the subjects filled in a post-experiment questionnaire. The questionnaire included questions on the driving and operating performance. The experiment group further answered questions on the tested gamified mobile application.

\subsubsection{Participants}

For the first test, we recruited 30 subjects between 19 and 28 years (median $=25$ years, standard deviation $\sigma=2.53$ ). There were 5 female and 25 male participants. Most of the participants were students or research assistants. The average experiment duration was 35 minutes. Subjects received a direct compensation for their participation in form of a $5 €$ gift card for an online retailer. The average driving experience was 6.0 years $(\sigma=2.53)$. The subjects were randomly assigned to the experiment and control group. A Student's t-test ( $\alpha=0.05$, two-tail) on the driving experiences of the control and the experiment group showed no significant difference $(\mathrm{P}(\mathrm{T} \leq \mathrm{t})=0.069)$. In addition, there were no significant differences in experience with and interest in technical devices between both groups.

\subsection{Results}

\subsubsection{Results of Driving Experiment}

The presentation of the results focuses on the parts relevant for providing answers to our research questions.

The analysis of the $L C T$ track deviation data gave the following results. In comparison to the second lap (ground truth) without additional operating tasks, the lane deviation increased for the control group on average about $48.7 \%(\sigma=0.43)$ for the third lap and $39.6 \%$ $(\sigma=0.46)$ for the fourth lap. The experiment group had slightly better results. Their lane deviation increased by $42.1 \%(\sigma=0.27)$ for the third lap and $23.7 \%(\sigma=0.27)$ for the fourth lap. However, no significant differences could be found between the results for both laps (lap 1: $\mathrm{P}(\mathrm{T} \leq \mathrm{t})=0.65$, lap 2: $\mathrm{P}(\mathrm{T} \leq \mathrm{t})=0.26)$. 


\begin{tabular}{|l|c|c|c|c|}
\hline \multirow{2}{*}{ Task } & \multicolumn{2}{|c|}{ Lap 1 } & \multicolumn{2}{c|}{ Lap 2 } \\
\cline { 2 - 5 } & $\begin{array}{c}\text { Control } \\
\mathrm{n}=15\end{array}$ & $\begin{array}{c}\text { Exp. } \\
\mathrm{n}=15\end{array}$ & $\begin{array}{c}\text { Control } \\
\mathrm{n}=14\end{array}$ & $\begin{array}{c}\text { Exp. } \\
\mathrm{n}=14\end{array}$ \\
\hline $\begin{array}{l}\text { Task 1: Increase volume } \\
\text { via steering wheel }\end{array}$ & $93.3 \%$ & $93.3 \%$ & $100 \%$ & $100 \%$ \\
\hline $\begin{array}{l}\text { Task 2: Change radio sta- } \\
\text { tion via steering wheel }\end{array}$ & $\mathbf{8 0 . 0} \%$ & $73.3 \%$ & $78.6 \%$ & $78.6 \%$ \\
\hline $\begin{array}{l}\text { Task 3: Play CD: Sheryl } \\
\text { Crow }\end{array}$ & $\mathbf{8 0 . 0} \%$ & $73.3 \%$ & $\mathbf{1 0 0} \%$ & $92.9 \%$ \\
\hline $\begin{array}{l}\text { Task 4: Activate Active } \\
\text { Cruise Control }\end{array}$ & $33.3 \%$ & $\mathbf{6 0 . 0} \%$ & $35.7 \%$ & $\mathbf{7 1 . 4} \%$ \\
\hline $\begin{array}{l}\text { Task 5: Start Navigation } \\
\text { to 'Home' }\end{array}$ & $\mathbf{7 3 . 3} \%$ & $66.7 \%$ & $\mathbf{1 0 0} \%$ & $78.6 \%$ \\
\hline
\end{tabular}

Table 2 Accomplishment rates for operating tasks. There were 15 participants in both groups for the first lap. For the second lap, in each group one subject decided to end the driving experiment early.

The task completion rates were almost equal for both groups (see Table 2). The only significant difference can be seen for task 4 . The completion rate for the active cruise control task is twice as high for the experiment group as for the control group.

The results from the subjective assessment of the mental workload with the NASA-TLX (weighted score from 0 to 100) correlate with the average lane deviation of the $L C T$. No significant difference was found between the groups. For the second lap (ground truth without operating task), an average NASA-TLX score of $24.7(\sigma=13.9)$ was calculated. The third lap (first experiment lap with operating tasks) had an average score of $57.0(\sigma=21.3)$, the fourth lap resulted in an average score of $39.4(\sigma=18.4)$. The average NASA-TLX scores of all users split up into categories are depicted in Fig. 4.

In addition, the subjects rated statements on the driving experiment on a 5 -point Likert scale ( $1=$ strongly disagree, $5=$ strongly agree). The results are summarized in Table 3. The goal was to measure whether the usage of the mobile application changes the perception of the driving task. However, no significant differences between both groups could be observed. 


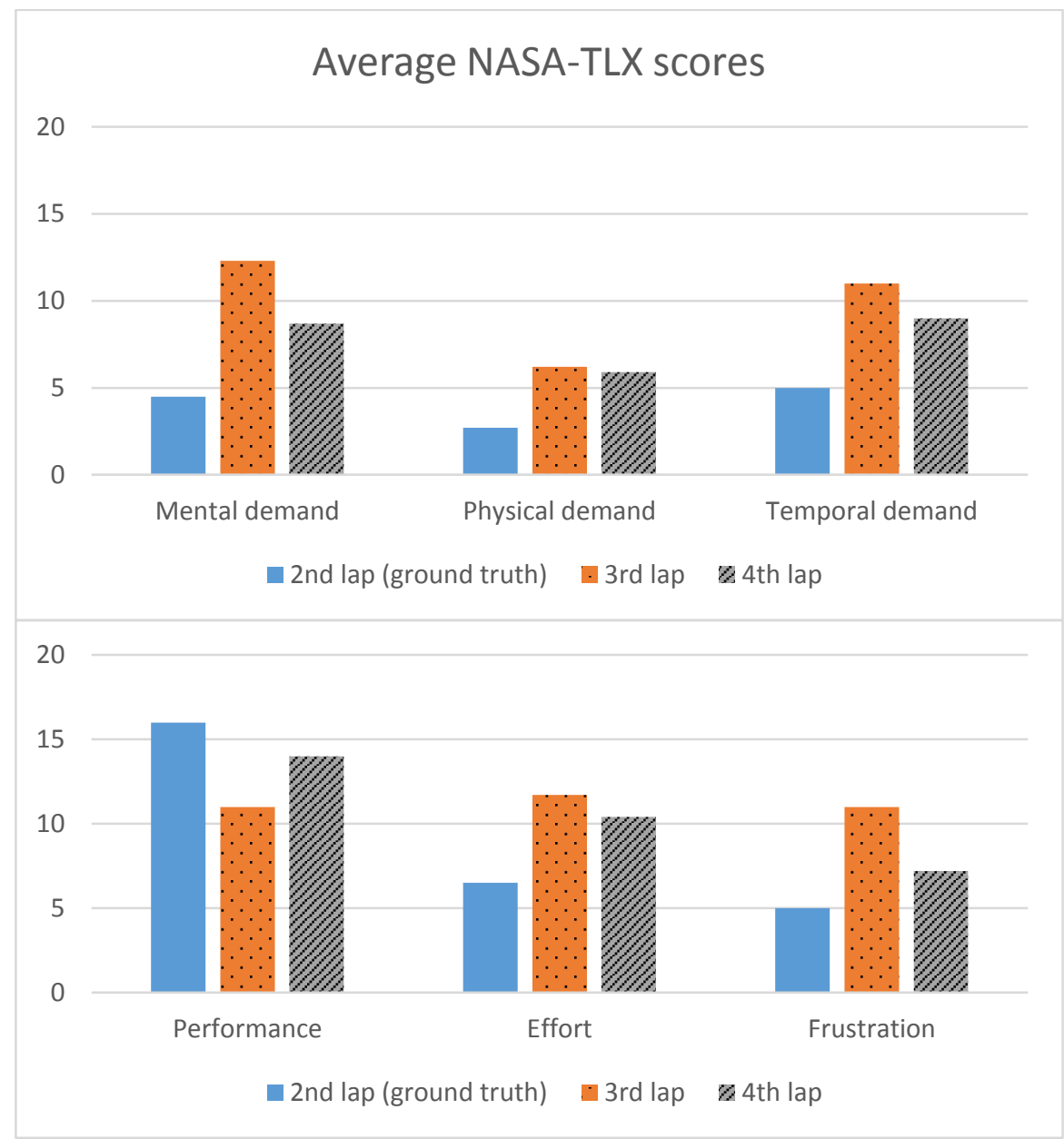

Figure 4 Average NASA-TLX scores for all subjects. The subject could assess the different categories on a scale from 0 to 20 with $0=$ very low and $20=$ very high. 


\begin{tabular}{|l|r|r|r|r|}
\hline \multirow{2}{*}{ Statement } & \multicolumn{2}{|c|}{ Control Group } & \multicolumn{2}{c|}{ Exp. Group } \\
\cline { 2 - 5 } & \multicolumn{1}{|c|}{ Mean } & \multicolumn{1}{c|}{$\sigma$} & \multicolumn{1}{c|}{ Mean } & \multicolumn{1}{c|}{$\sigma$} \\
\hline $\begin{array}{l}\text { The operating tasks were } \\
\text { too difficult for me. }\end{array}$ & 2.07 & 0.59 & 1.87 & 0.74 \\
\hline $\begin{array}{l}\text { My goal was to drive } \\
\text { safely. }\end{array}$ & 3.27 & 1.03 & 3.67 & 0.98 \\
\hline $\begin{array}{l}\text { My goal was to accom- } \\
\text { plish the tasks quickly. }\end{array}$ & 4.34 & 0.62 & 4.27 & 0.70 \\
\hline $\begin{array}{l}\text { My goal was to reach a } \\
\text { high score. }\end{array}$ & 4.07 & 1.03 & 4.20 & 0.77 \\
\hline $\begin{array}{l}\text { The experiment felt more } \\
\text { like a game for me. }\end{array}$ & 3.47 & 0.92 & 3.34 & 1.05 \\
\hline
\end{tabular}

Table 3 Mean and standard deviation $(\sigma)$ of rated statements concerning the driving experiment. The statements had to be rated on a 5-point Likert scale with $1=$ 'strongly disagree' and $5=$ 'strongly agree'. No significant differences between the control group and the experiment group can be observed.

\subsubsection{Results related to the Mobile Application}

The subjects in the experiment group $(\mathrm{n}=15)$ further rated statements on the mobile application on a 5 -point Likert scale $(1=$ strongly disagree, $5=$ strongly agree). The fun factor of the application was rated with an average score of $4.20(\sigma=0.56)$. The usefulness of the application was confirmed with an average rating of $4.27(\sigma=0.46)$. The subjects can further think of using such an application for unknown cars (mean $=3.80, \sigma=0.77$ ). Participants further thought that the use of the application made the operating tasks easier during the driving experiment (mean $=4.47, \sigma=0.52$ ). Regarding the motivation, the subjects stated with an average score of $4.73(\sigma=0.46)$ that the quiz mode with the ability to make a high score motivated them to improve their initial score. 


\subsection{Discussion}

Based on the results from the performed experiment, answers to the research questions shall be provided in the discussion of the results.

\subsubsection{Influence of Gamification on the Training Motivation (RQ1)}

Subjects in the experiment group clearly stated that the possibility to improve their score in the quiz mode of the mobile application was a good incentive to perform the quiz several times. However, so far the quiz mode only asks for the location of input elements. For that reason, the quiz can quickly become boring. Subjects suggested to implement different categories of questions or to ask multiple-choice questions on the operating elements and their functions. In addition, the idea of unlocking new application features by exploring the virtual cockpit was appealing.

The individual statements of the subjects match with the rating of the application presented in Section 7.2.1. In summary, game elements had a positive influence on the training motivation. However, users need the feeling that the quiz evolves with their growing expertise.

\subsubsection{Influence of Gamification on the Driving Performance (RQ2)}

Although the subjects in the experiment group stated in the post-questionnaire that the use of the gamified mobile application had helped them during the driving experiment, no significant difference in the $L C T$ results could be observed compared to the results of the control group (see Section 7.2.1). That means that the training application had no direct influence on the driving performance.

For the operation tasks, the results were comparable for both groups. The only significant difference was in task 4, which was the activation of the active cruise control. This was the only function in our operation task set that is not yet widely available and had to be operated through a small lever located behind the steering wheel. This indicates that the mobile training application is beneficial for functions that are not yet common in cars and/or are not plainly visible. 


\subsubsection{Influence of Gamification on Recommendations (RQ3)}

Subjects stated in the final interviews that the mobile application had both informative and game character. Especially the cockpit view and the function list have been seen as an information source. The quiz mode was rated to be more like a 'learning game.' However, when we observed the users interacting with the mobile application, we noticed that the informative character faded into the background. Most subjects tapped systematically or completely randomly on the virtual cockpit in order to find all functions. When a function was found, the description was often just quickly scanned and possible recommendations or usage hints were overlooked. When we mentioned this in the interview, the subjects stated that their goal was to activate the quiz mode quickly.

\subsubsection{Negative Aspects of Gamification (RQ4)}

One negative aspect of gamification was already mentioned in Section 7.3.3. Instead of reading the information, subjects tried to keep the game flowing. A solution could be to implement a short compulsory break that allows the user to read the text. Another idea is to cut down the amount of information presented at a time. Alternatively, the textual explanation of functions could be enhanced with interactive graphics, video snippets, or audio.

For evaluating the game element 'score' and, thus, 'competition,' a score was computed during the driving experiment and displayed to the subjects after completing a lap. We further intensified the 'competition' after the first lap by saying that they can enter a high-score list when they get more points in the second lap. From the values in Table 3, it can be seen that on average the subjects concentrated more on the operating tasks and their score than on driving safely. Although both groups had only slightly the feeling that the experiment is more like a game (see Table 3), they disregarded the instruction that the main objective was to drive safely. When we asked the subjects why they had concentrated on the score, they mainly named the competition as decisive factor. The high-score list influenced even subjects who stated in the pre-experiment questionnaire not to be very competitive. 


\section{Towards Guidelines for Gamification in the Automotive Domain}

The experiences gathered during the development and the first laboratory test with the framework could serve as a basis for future gamified automotive applications as well as their evaluation. The following statements summarize our findings:

Abstraction can be dangerous, details also: Games often abstract complex tasks in order to offer a better game flow experience (see Section 5). However, especially when gamifying real processes that could cause safety issues, the precision and accuracy has to meet the requirements of the process. For example, in a first version, we only delivered a very short and simplified description for the adaptive cruise control stalk switch, which lead to situation where subjects did not know how the set speed of the ACC could be reset. Some subjects activated the adaptive cruise control and the car in the simulation accelerated automatically to more than double the predetermined speed. However, also too much details can be dangerous during driving. Following the rule of immediate feedback (cf. Section 5), we created different icons with a short reward text that were shown on the dashboard of the simulator as soon as a task was solved. The message was only shown when the car drove straight and at a constant speed. However, some participants found these reward messages so interesting that they partially ignored the primary driving task they should focus on. Therefore, when designing a gamified application one has to find a balance for the right degree of detail and abstraction and how unambiguous feedback can be provided.

Make game rules clear: In our first experiments, we tried to hide the game mechanics, and did not offer an explanation on how points or awards can be earned. However, as soon as the subjects found out that they got points for a certain action, they repeated this action as often as possible to get as many points as possible. This led to drastic performance drops as the subjects' focus was on finding out the rules for getting more points. As already stated in Section 2, rules are important parts of games and need to be clear for the "players" (McGonigal 2011, p. 29ff). 


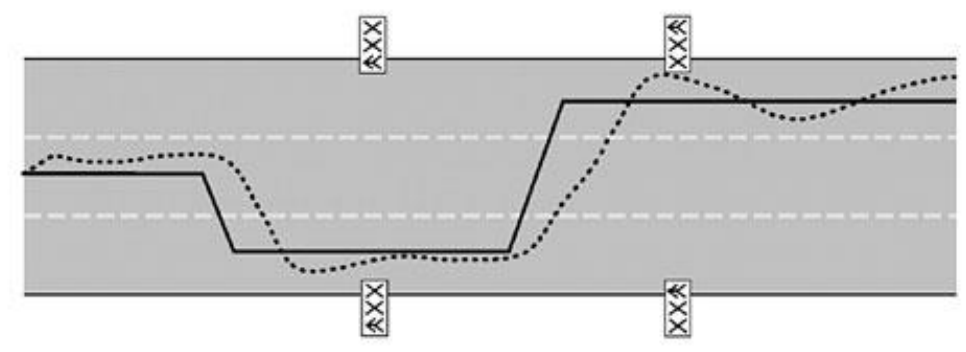

Fig. 4 The figure presents an example output of the track analysis tool of the Lance Change Task (LCT). The solid black line depicts the ideal track; the dotted line indicates the track driven by a subject during a task. By calculating the area between the two lines, the quality of the track keeping can be analyzed. This allows drawing conclusions on the subjects' distraction.

Test in a non-gaming context: The first iterations of the framework prototype were tested with a computer steering wheel in front of two large displays on a desk. The driving simulation software was similar to Geoquake's 3D Google Maps simulation ${ }^{18}$. Already during the first test rounds, we noticed that most participants had the feeling that the situation was unreal and more like a game. For that reason, we changed to the realistic car cockpit simulator afterwards (see Fig. 3). This hugely changed the perception of the subjects (see Table 3). On the software side, we changed from our own satellite image-based simulation tool to the established Lane Change Task. Its analysis tool further allows measuring the lane deviation (see Fig. 4) and comparing the subjects' driving performance when performing secondary or tertiary tasks with their baseline driving when they only concentrate on the driving. In our experience, one can only find out the caused gaming effect of a gamified application, when it is tested in a non-gaming context, i.e. with a realistic driving simulation or a real car. In that way, it can be found out whether the gamified system has an influence on the seriousness of the driving task.

Do not gamify the task of driving: An important aspect we noticed during the experiment was that a gamified automotive application should not gamify the task of driving. For example, at an early stage, our framework suggested to use a different input modality for

${ }^{18} \mathrm{http} / /$ geoquake.jp/en/webgame/DrivingSimulatorPerspective/, last accessed September 27, 2013. 
controlling a function when it noticed that the driver left the lane during an operation task, and awarded points when the driver successfully used the suggested modality (Diewald et al. 2012). Although the application chose the drivers' preferred modality, the subjects mainly concentrated on gaining points and the driving performance drastically decreased.

Our results further show that competition is a very motivating factor for users to lose focus from the primary driving task (see Section 7.3.4). This coincides also with the observations of Deterding presented in Section 3.2.2, which means that competition for safety critical applications should be avoided.

The most important experiences from the tests during the development however were that the concept should be developed iteratively and that after each slight change of the game mechanics a test is necessary. Even the change from one game element to another can be critical and needs to be evaluated thoroughly. 


\section{Conclusion and Future Work}

In this chapter, we first looked at common game elements and mechanics and then analyzed several examples of gamified applications in the automotive domain and for learning environments. Based on these analyses, we brought out limitations and challenges of gamification in the automotive domain, which were considered when creating our proposed gamified framework for exploring automotive user interfaces and practicing vehicle functions. After presenting the concept and implementation of this framework, we summarized the results from our first study. Based on these results and experiences during the development, we formulated some guidelines that we share in order to support further research on gamification in the automotive domain.

We are currently enhancing the mobile application and conducting an experiment with the online mode of the framework. We will investigate whether the training effect with a recreated virtual car interface (offline mode) is comparable to the effect when training with a real car interface (online mode). The comparison of the offline mode and the online mode will also be used to determine whether gamification in the real car distorts the perception of the seriousness of 'driving a real car'.

Although gamification also has several negative aspects that need to be considered, we are convinced that our approach could improve the situation for people who often switch cars, but want to have stressfree and comfortable rides.

Acknowledgments We gratefully acknowledge the assistance in research and implementation of our student Duc Ha Minh and thank the Institute for Human-Machine Communication at Technische Universität München for letting us use their driving simulator.

\section{References}

Abt, C. C. (2002). Serious Games. University Press of America.

Alonso, M., Vega, M. H., \& Martín, O. (2012). Driving Simulation Study for the Analysis of Distraction Effects in Longitudinal 
Driving Behaviour. Cognition, Technology \& Work, 14(4), 283-297. doi:10.1007/s10111-011-0180-9

Connolly, T. M., Boyle, E. A., MacArthur, E., Hainey, T., \& Boyle, J. M. (2013). A Systematic Literature Review of Empirical Evidence on Computer Games and Serious Games. Comput. Educ., 59(2), 661-686. doi:10.1016/j.compedu.2012.03.004

Deci, E. L. (1972). Intrinsic Motivation, Extrinsic Reinforcement, and Inequity. Personality and Social Psychology, 22(1), 113-120.

Deci, E. L., Koestner, R., \& Ryan, R. M. (2001). Extrinsic Rewards and Intrinsic Motivation in Education: Reconsidered Once Again. Review of Educational Research, 71(1), 1-27.

Deterding, S., Dixon, D., Khaled, R., \& Nacke, L. (2011). From Game Design Elements to Gamefulness: Defining "Gamification". Proceedings of the 15th International Academic MindTrek Conference: Envisioning Future Media Environments (pp. 915). Tampere, Finland: ACM. doi:10.1145/2181037.2181040

Diewald, S., Möller, A., Roalter, L., \& Kranz, M. (2012). Gamification-supported Exploration of Natural User Interfaces. Adjunct Proceedings of the 4th International Conference on Automotive User Interfaces and Interactive Vehicular Applications, (pp. 47-48). Portsmouth, NH, USA.

Diewald, S., Möller, A., Roalter, L., Stockinger, T., \& Kranz, M. (2013). Gameful Design in the Automotive Domain: Review, Outlook and Challenges. Proceedings of the 5th International Conference on Automotive User Interfaces and Interactive Vehicular Applications (pp. 262-265). Eindhoven, Netherlands: ACM. doi:10.1145/2516540.2516575

Domínguez, A., Saenz-de-Navarrete, J., de-Marcos, L., FernándezSanz, L., Pagés, C., \& Martínez-Herráiz, J.-J. (2013). Gamifying Learning Experiences: Practical Implications and Outcomes. Computers \& Education, 63(1), 380-392. doi:10.1016/j.compedu.2012.12.020

Ecker, R., Holzer, P., Broy, V., \& Butz, A. (2011). EcoChallenge: A Race for Efficiency. Proceedings of the 13th International Conference on Human Computer Interaction with Mobile Devices and Services. Stockholm, Sweden: ACM. doi:10.1145/2037373.2037389

Fitz-Walter, Z., Tjondronegoro, D., \& Wyeth, P. (2011). Orientation Passport: Using Gamification to Engage University Students. 
Proceedings of the 23rd Australian Computer-Human Interaction Conference (pp. 122-125). Canberra, Australia: ACM. doi:10.1145/2071536.2071554

Harbluk, J. L., Burns, P. C., Lochner, M., \& Trbovich, P. L. (2007). Using the Lane-change Test (LCT) to Assess Distraction: Tests of Visual-manual and Speech-based operation of Navigation System Interfaces. Proceedings of the Fourth International Driving Symposium on Human Factors in Driver Assessment, Training and Vehicle Design, (pp. 16-22). Stevenson, WA, USA.

Hsu, C.-L., \& Lu, H.-P. (2004, September). Why Do People Play Online Games? An Extended TAM With Social Influences and Flow Experience. Information and Management, 41(7), 853868. doi:10.1016/j.im.2003.08.014

Hunicke, R., Leblanc, M., \& Zubek, R. (2004). MDA: A Formal Approach to Game Design and Game Research. Proceedings of the Challenges in Games AI Workshop at the 19th National Conference of Artificial Intelligence, (pp. 1-5).

Inbar, O., Tractinsky, N., Tsimhoni, O., \& Seder, T. (2011). Driving the Scoreboard: Motivating Eco-Driving Through In-Car Gaming. CHI 2011 Workshop Gamification: Using Game Design Elements in Non-Game Contexts. Vancouver, BC, Canada.

Kern, D., \& Schmidt, A. (2009). Design Space for Driver-based Automotive User Interfaces. Proceedings of the 1st International Conference on Automotive User Interfaces and Interactive Vehicular Applications (pp. 3-10). Essen, Germany: ACM. doi:10.1145/1620509.1620511

Kranz, M., Möller, A., Hammerla, N., Diewald, S., Plötz, T., Olivier, P., \& Roalter, L. (2013). The Mobile Fitness Coach: Towards Individualized Skill Assessment Using Personalized Mobile Devices. Pervasive and Mobile Computing, 9(2), 203-215. doi:10.1016/j.pmcj.2012.06.002

Kranz, M., Murmann, L., \& Michahelles, F. (2013). Research in the Large: Challenges for Large-Scale Mobile Application Research - A Case Study about NFC Adoption using Gamification via an App Store. International Journal of Mobile Learning and Organization, 5(1), 45-61. doi:10.4018/jmhci.2013010103 
Li, W., Grossman, T., \& Fitzmaurice, G. (2012). GamiCAD: a Gamified Tutorial System for First Time AutoCAD Users. Proceedings of the 25th Annual ACM Symposium on User Interface Software and Technology, (pp. 103-112). Cambridge, MA, USA. doi:10.1145/2380116.2380131

Malone, T. W. (1980). What makes things fun to learn? heuristics for designing instructional computer games. Proceedings of the 3rd ACM SIGSMALL Symposium and the 1st SIGPC Symposium on Small Systems (pp. 162-169). Palo Alto, CA, USA: ACM. doi:10.1145/800088.802839

McCall, R., \& Koenig, V. (2012). Gaming Concepts and Incentives to Change Driver Behaviour. Proceedings of the 11th Annual Mediterranean Ad Hoc Networking Workshop, (pp. 146-151). Ayia Napa, Cyprus.

McCallum, S. (2012). Gamification and Serious Games for Personalized Health. Studies in Health Technology and Informatics, 177, 85-96.

McGonigal, J. (2011). Reality Is Broken: Why Games Make Us Better and How They Can Change the World. The Penguin Group.

Merugu, D., Prabhakar, B. S., \& Rama, N. S. (2009). An Incentive Mechanism for Decongesting the Roads: A Pilot Program. Proceedings of the ACM Workshop on the Economics of Networked Systems. ACM.

Michael, D. R., \& Chen, S. (2005). Serious Games: Games That Educate, Train, And Inform. Thomson Course Technology.

Möller, A., Thielsch, A., Dallmeier, B., Roalter, L., Diewald, S., Hendrich, A., Meyer, B., Kranz, M. (2011). MobiDics Improving University Education With A Mobile Didactics Toolbox. Video Proceedings of the 9th International Conference on Pervasive Computing. San Francisco, CA, USA.

Muntean, C. I. (2011). Raising Engagement in E-Learning through Gamification. Proceedings of the 6th International Conference on Virtual Learning, (pp. 323-329). Taipei, Taiwan.

NHTSA. (2009). Traffic Safety Facts - Research Note DOT HS 811 216. Washington, DC, USA: U.S. Department of Transportation. 
Novick, D. G., \& Ward, K. (2006). Why don't people read the manual? Proceedings of the 24th International Conference on Design of Communication, (pp. 11-18). Myrtle Beach, SC, USA. doi:10.1145/1166324.1166329

Rouzikhah, H., King, M., \& Rakotonirainy, A. (2013). Examining the Effects of an Eco-driving Message on Driver Distraction. Accident Analysis \& Prevention, 50(1), 975-983. doi:10.1016/j.aap.2012.07.024

Shi, C., Lee, H. J., Kurczak, J., \& Lee, A. (2012). Routine Driving Infotainment App: Gamification of Performance Driving. Adjunct Proceedings of the 4th International Conference on Automotive User Interfaces and Interactive Vehicular Applications, (pp. 181-183). Portsmouth, NH, USA.

Simões, J., Redondo, R. D., \& Vilas, A. F. (2013). A Social Gamification Framework for a K-6 Learning Platform. Computers in Human Behavior, 29(2), 345-353. doi:10.1016/j.chb.2012.06.007

Stockinger, T., Koelle, M., Lindemann, P., Witzani, L., \& Kranz, M. (2013). SmartPiggy: A Piggy Bank That Talks to Your Smartphone. Proceedings of the 12th International Conference on Mobile and Ubiquitous Multimedia (pp. 42:142:2). Luleå, Sweden: ACM. doi:10.1145/2541831.2541869

Tillström, J. (2012). Gamification in Automotive Marketing - A Conceptual Framework for Implementation. Helsinki: Helsinki Metropolia University of Applied Sciences.

Tractinsky, N., Inbar, O., Tsimhoni, O., \& Seder, T. (2011). Slow Down, You Move Too Fast: Examining Animation Aesthetics to Promote Eco-driving. Proceedings of the 3rd International Conference on Automotive User Interfaces and Interactive Vehicular Applications (pp. 193-202). Salzburg, Austria: ACM. doi:10.1145/2381416.2381447

Zichermann, G., \& Cunningham, C. (2011). Gamification by Design: Implementing Game Mechanics in Web and Mobile Apps. O'Reilly Media.

Zyda, M. (2005). From Visual Simulation to Virtual Reality to Games. Computer, 38(9), 25-32. doi:10.1109/MC.2005.297 